\title{
Post-radiation retinopathy
}

\section{A fluorescence fundus angiographic study}

\author{
SOHAN SINGH HAYREH \\ Institute of Ophthalmology, University of London
}

Irradiation of the posterior segment of the eye resulting from radiotherapy either of local ocular lesions (e.g. retinoblastoma or malignant melanoma of the choroid) or of extraocular lesions of the adjacent regions (e.g. carcinoma of the antrum and nose, rodent ulcer of the face, squamous cell carcinoma of eyelids, etc.) has been known to produce delayed retinal vascular changes which develop many months or years after the actual irradiation, and may cause disturbances of vision. Stallard (1933, 1936) first reported these changes in a case of retinoblastoma treated by implantation of radon seeds. He found a circinate type of retinopathy with retinal haemorrhages and exudates, oedema of the optic disc, and sheathing of the central retinal vessels 20 months after irradiation, which ultimately caused optic atrophy. Post-radiation retinal vascular lesions have since been reported by many authors, including Foster Moore (1 935), Pillat (1935), Renard and Duriez (1949), Martin and Reese (1942, I945), Fry (1952), Cogan (1950, I958), Stallard (1959, I96 I, i966), Perrers-Taylor, Brinkley, and Reynolds (1965), Howard (1966), Chee (1968), Gass (1968), MacFaul and Bedford (1970), and Bedford, Bedotto, and MacFaul (1970).

The use of fluorescence fundus angiography in various types of retinopathy in the recent past has given us hitherto unknown information on the subject. A brief account of fluorescence fundus angiographic findings in post-radiation retinopathy has previously been reported in only two cases (Gass, I968, and Chee, I968- the same cases being reported by the two authors).

Recently, post-radiation retinopathy was noticed in three cases of malignant melanoma of the choroid treated by Cobalt-6o application at Moorfields Eye Hospital, London (Bedford and others, 1970). These three cases have been investigated by fluorescence fundus angiography. This study has revealed some interesting retinal vascular changes which are reported in detail in this paper. A pattern of post-radiation retinopathy based on these findings is described, as no such detailed account on the subject is available in the literature.

\section{Observations}

The three eyes of the present series showed the following lesions after irradiation:

\section{Case I, a 50-year-old man}

A malignant melanoma of the choroid in the inferior nasal quadrant of the fundus was treated with a circular Cobalt-6o plaque, giving a dose of 8,00o $r$ to the summit of the tumour. In the course of 6 months' treatment the tumour flattened and showed no sign of activity; 8 months after the treat- 
ment, retinal haemorrhages were seen close to the optic disc. Fig. I B shows the superior temporal quadrant of the fundus i I months after treatment. After a further year, when the previous retinal lesions showed resolution, fresh lesions were seen in the macular region and inferior temporal quadrant, and the superior nasal quadrant showed retinal haemorrhages.

FLUORESGENGE FUNDUS ANGIOGRAPHY

Pre-treatment

A pattern of malignant melanoma of the choroid was seen, i.e. fluorescence of the lesion during the arterio-venous phase of the transit of the dye with late fluorescence (Hayreh, i970).

I months after irradiation

Flame-shaped retinal haemorrhages, microaneurysms, cotton-wool spots, and retinal oedema due to occlusion of small retinal vessels and capillaries were seen in the superior-temporal sector adjacent to the optic disc, but the main retinal vessels and the cilio-retinal arteries were still patent (Fig. I A, B). The optic disc showed some leakage of fluorescein from the surface vessels with no other abnormality.

( IA)

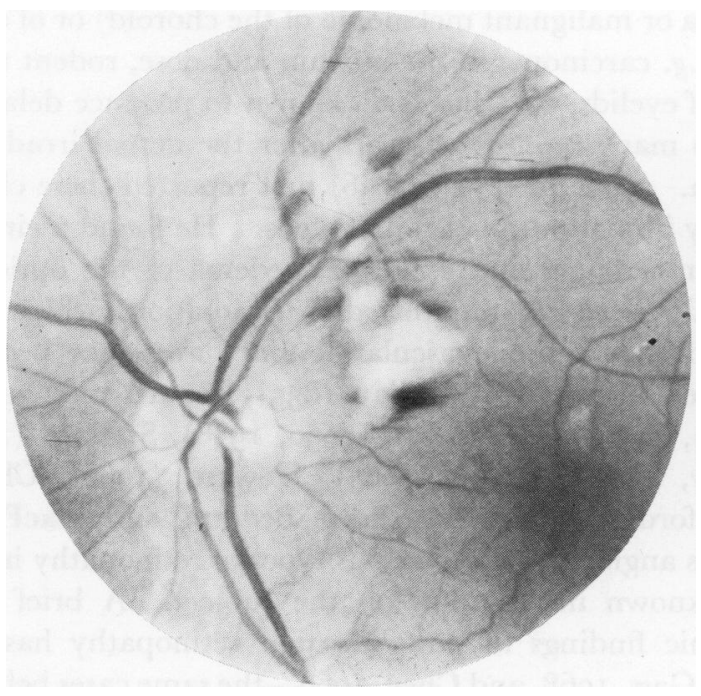

( $\mathbf{I B})$

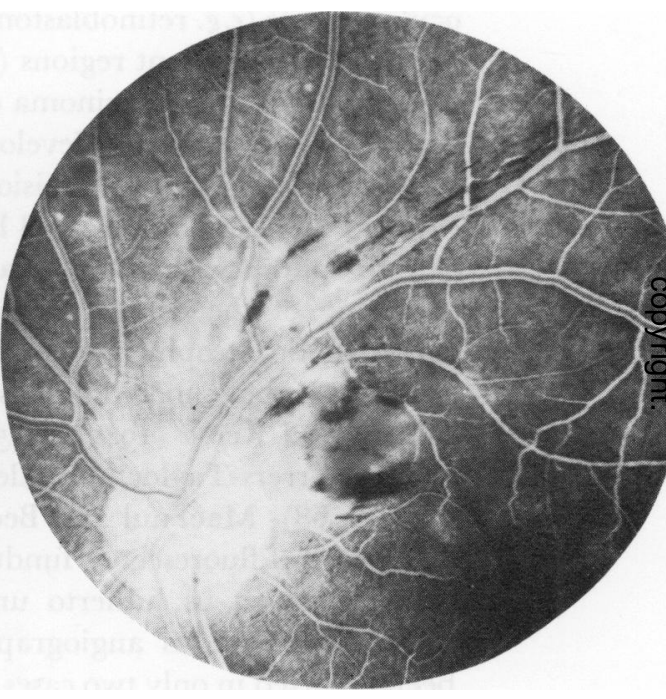

FIG. I Fundus of Case I.

FIG. I A Photograph showing haemorrhages and cotton-wool spots along superior temporal vessels (I I months after irradiation)

FIG. I B Fluorescence angiogram (early arterio-venous phase), showing focal absence of capillaries in areas of cotton-wool spots, with normal circulation in superior temporal vessels (I I months after irradiation)

In the irradiated zone, the retinal vessels were attenuated with no evidence of retinopathy in this region. The irradiated area showed an accumulation of non-fluorescent grey pigment and was surrounded by atrophic choroid where the disappearance of the vessels was inversely related to their size. The overlying pigment epithelium was also atrophic in this area.

22 months after irradiation

The inferior temporal quadrant and the macular region showed a large patch of retinopathy with haemorrhages, microaneurysms, cotton-wool spots, a few white deposits, and retinal oedema (Fig. IC). The branch of the inferior temporal arteriole supplying this region was occluded (Fig. ID, E). From the optic disc margin to a little distance beyond the area of retinopathy, no branch was seen to arise from the inferior temporal arteriole. In the area of retinopathy, venous telangiectases were 

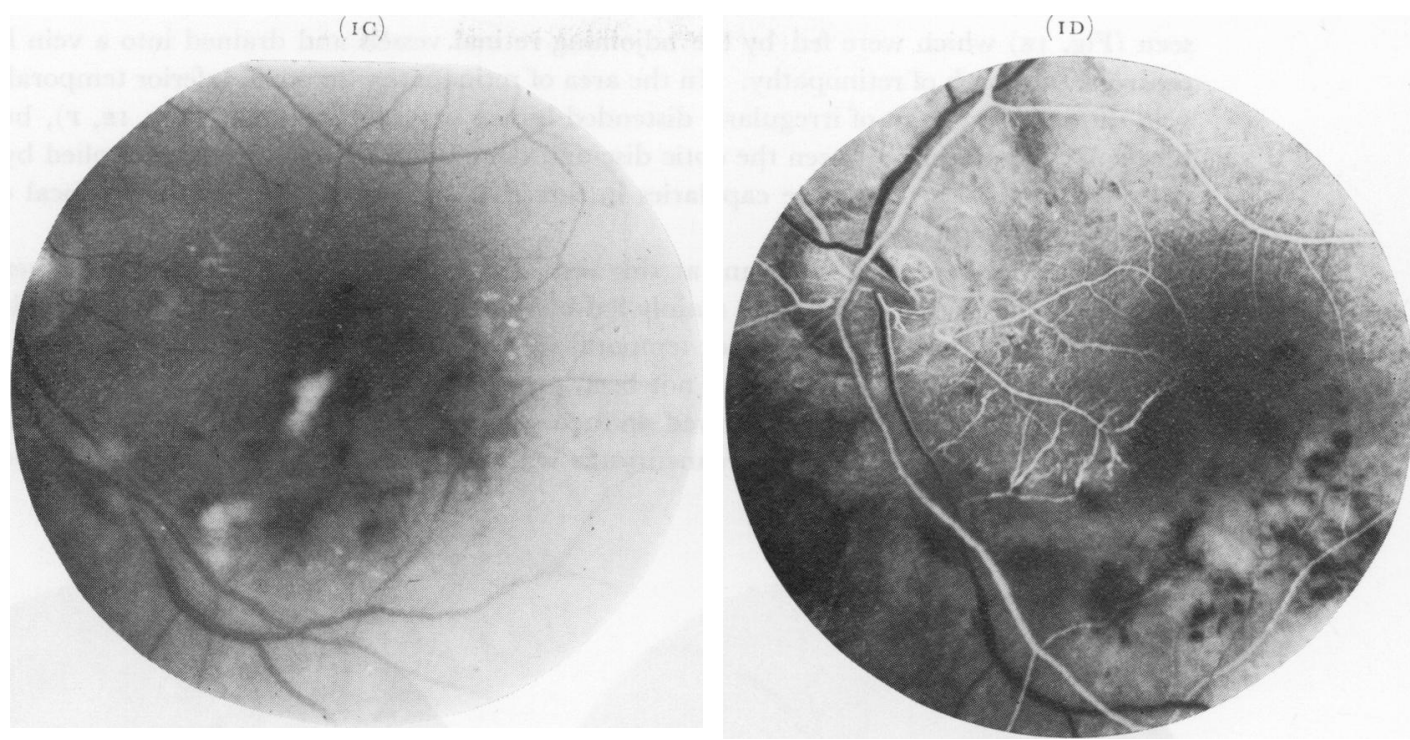

FI I. I C Photograph of central area, showing haemorrhages, cotton-wool spots, and white deposits in macular region and along inferior temporal vessels (22 months after irradiation)

FIG. ID Fluorescence angiogram (arterial phase), showing filling of main retinal arterioles, cilio-retinal arteries, and vessels of ciliary origin in the disc (22 months after irradiation)
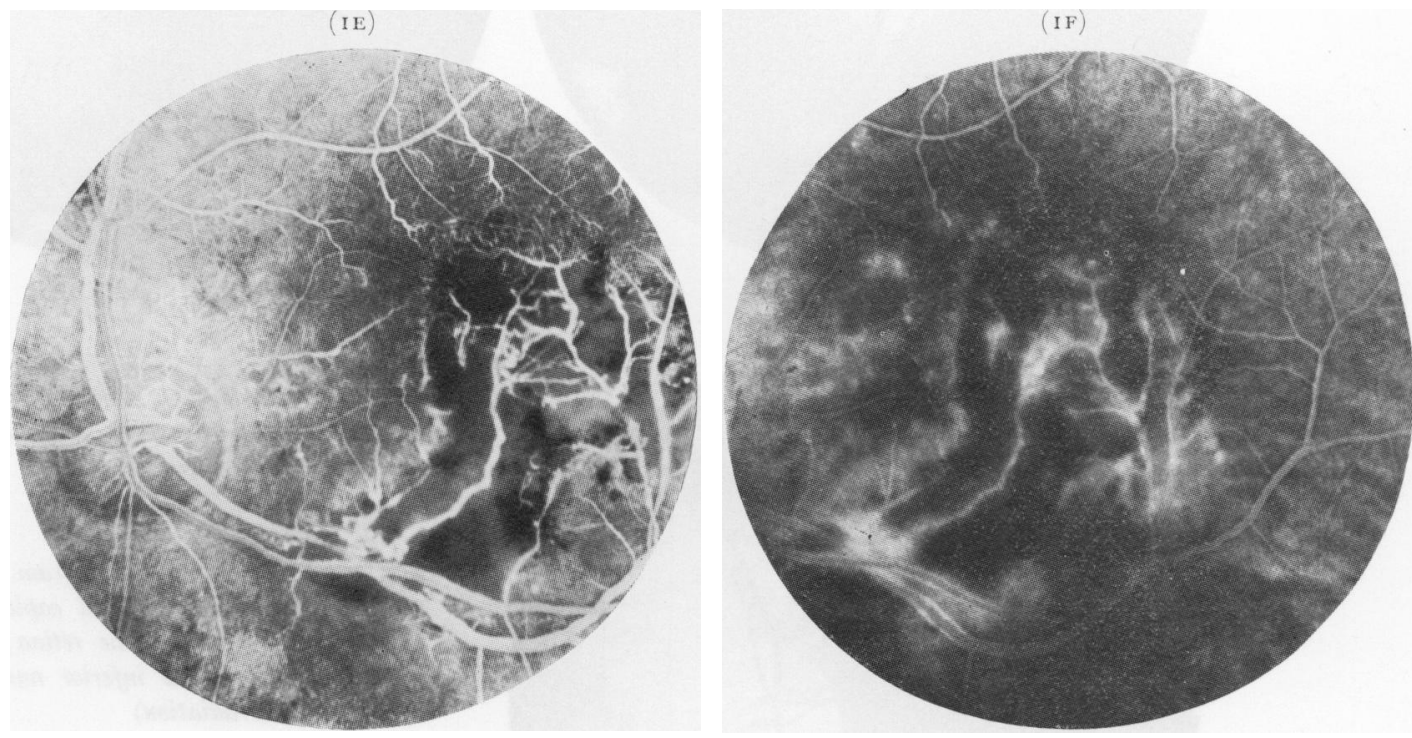

FIG. IE Fluorescence angiogram (late arterio-venous phase), showing absence of arterial and capillary vessels in infarcted area with telangiectases, as well as focal capillary occlusion and microaneurysms in the retina temporal to the disc. Segmental dilatation and perivasculitis of inferior temporal vessels are seen in the region of the infarct (22 months after irradiation)

FIG. I F Fluorescence angiogram (after the end of venous phase) showing leakage of fluorescein from abnormal vessels and microaneurysms, and segmental perivascular fluorescent sheathing of the inferior temporal vessels due to perivasculitis 
seen (Fig. IE) which were fed by the adjoining retinal vessels and drained into a vein lying in the centre of the patch of retinopathy. In the area of retinopathy the main inferior temporal artery and vein showed a segment of irregularly distended lumen with perivasculitis (Fig. IE, F), but were not blocked. The retina between the optic disc and the area of retinopathy was supplied by one of the three cilio-retinal arteries; the capillaries in this area also showed small areas of focal obliteration and some microaneurysms.

The superior temporal quadrant at this time showed only two small haemorrhages (Fig. IG). The capillaries in this region were mainly fed by the cilio-retinal artery and showed multiple microaneurysms (Fig. IH). The superior temporal vein, particularly its first tributary going up, showed distortion (Fig. IG, H, I) which had not been present I I months before (Fig. IA, B).

The superior nasal quadrant showed an area of punctate haemorrhages. Angiography revealed focal capillary occlusion and microaneurysms with perivasculitis of the main retinal vessels in the affected area (Fig. IG, H, I).
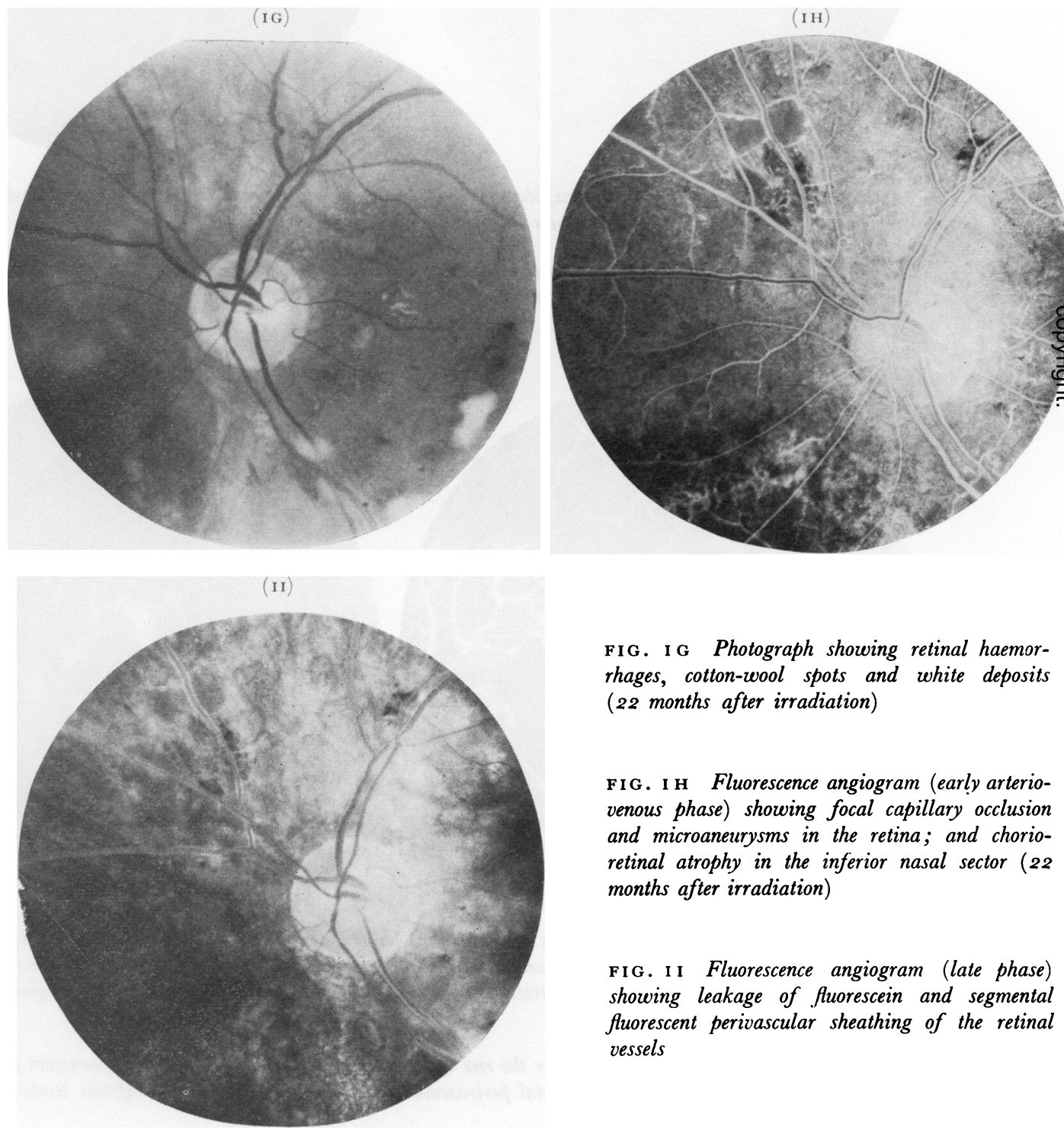

FIG. I G Photograph showing retinal haemorrhages, cotton-wool spots and white deposits (22 months after irradiation)

FIG. I H Fluorescence angiogram (early arteriovenous phase) showing focal capillary occlusion and microaneurysms in the retina; and chorioretinal atrophy in the inferior nasal sector (22 months after irradiation)

FIG. I I Fluorescence angiogram (late phase) showing leakage of fluorescein and segmental fluorescent perivascular sheathing of the retinal vessels 
The optic disc showed normal filling of the ciliary vessels to the disc except in the inferior nasal sector (Fig. ID). The surface nerve fibre capillaries showed no significant obliteration. The three cilio-retinal arteries filled normally. There was no optic atrophy.

The vessels in all the areas of retinopathy showed leakage of fluorescein during the late phases (Fig. IF, I).

\section{Case 2, a 51-year-old woman}

A malignant melanoma of the choroid which almost surrounded the optic disc in the right eye was irradiated with a C-shaped Cobalt-6o plaque applied to the posterior pole of the eye, giving an estimated dose of 8,00o $\mathrm{r}$ to the summit of the tumour. Io months after the course of treatment the lesion was flat with radiation scarring, and 12 months later, haemorrhages and exudates below the optic disc and white sheathing of the upper nasal retinal vessels were noted. 2 years after this (i.e. nearly 4 years after concluding the treatment), the upper nasal retinal vessels showed marked radiation changes with extension of the sheathing out to the periphery (Fig. 2A).
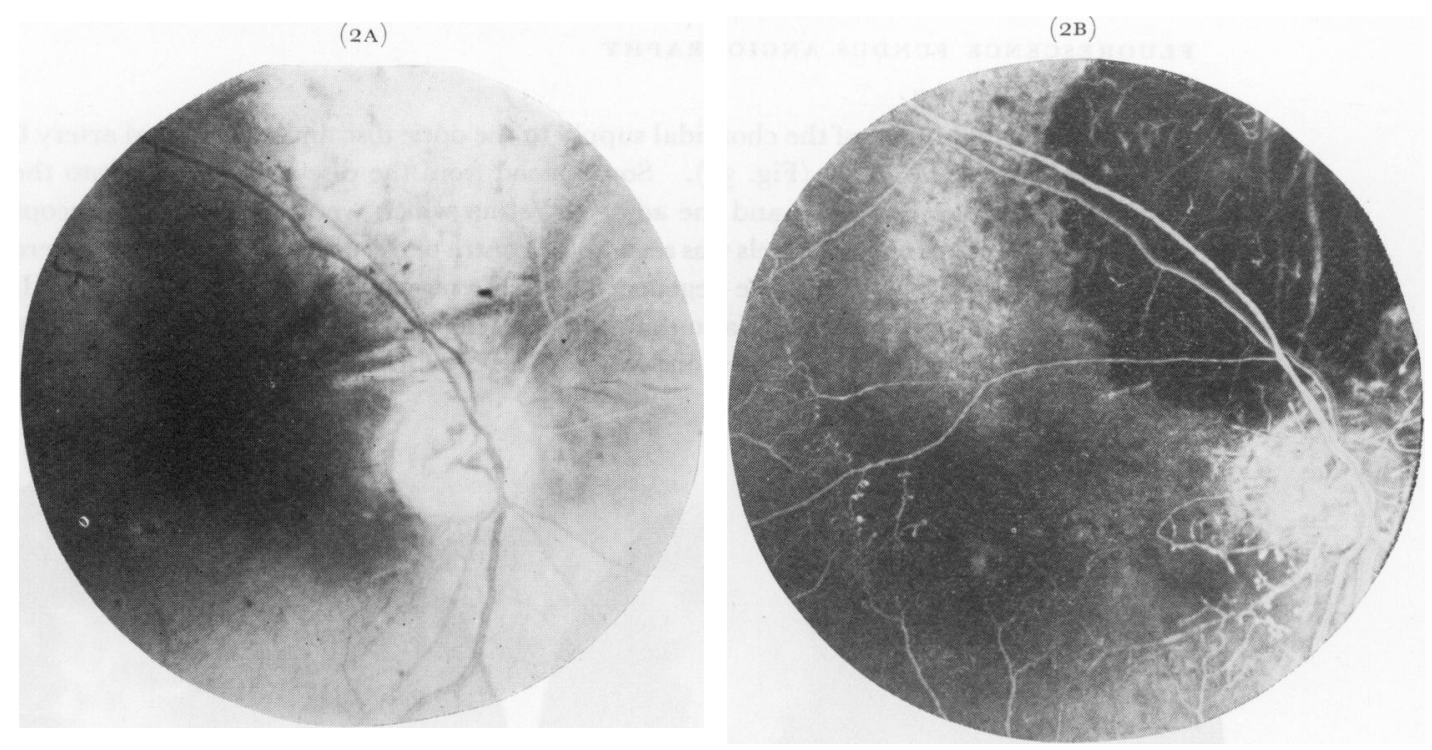

FIG. 2 Fundus of Case 2, 4 years after irradiation of malignant melanoma of choroid

FIG. 2 A Photograph showing extensive choroidal atrophy above optic disc in treated area, sheathing of superior nasal retinal vessels, new vessels on optic disc with pale disc, and a circular macular lesion

FIG. 2B Fluorescence angiogram (arterio-venous phase), showing filling of retinal vessels except for superior nasal vessels; absence of capillaries in macular region and upper part of retina, in addition to their focal obliteration and microaneurysms; and choroidal atrophy in irradiated area

\section{FLUORESCENGE FUNDUS ANGIOGRAPHY}

About 4 years after irradiation

There was complete occlusion of the superior nasal retinal vessels with normal circulation in the remaining main retinal vessels (Fig. 2A, B); the superior temporal vessels were, however, moderately attenuated. The capillaries were obliterated all round the optic disc (maximal above, nasally and temporally), in the retina above, and in the macular region (Fig. 2B). Microaneurysms were seen all round the optic disc and at the borders of the areas with obliterated capillaries as well as on the surface of the optic disc. The optic disc was atrophic; the vessels of choroidal origin showed normal 
filling at the disc and a leash of new vessels was seen on its surface in the centre which filled from the deeper ciliary circulation (Fig. 2A, B) - an attempt at cilio-retinal anastomoses. Fluorescein leaked from the microaneurysms and new vessels on the disc, producing marked fluorescence of the disc. The centre of the macula showed a circular patch of degeneration of the pigment epithelium (Fig. 2A, B). The irradiated area showed obliteration of the choroidal vessels, the extent of obliteration being inversely proportional to their size, with no retinopathy in this area (Fig. 2B).

\section{Case 3, a 53-year-old man}

A malignant melanoma of the choroid in the superior nasal quadrant was treated with a Cobalt-6o plaque applied over the base of the tumour, giving a dose of $8,000 \mathrm{r}$ to the summit of the tumour. In the course of 6 months the tumour regressed to inactivity but a haemorrhage appeared close to the optic disc on the nasal side. A year after the treatment, marked retinal vascular changes appeared, and 2 months after this a sudden central retinal artery occlusion led to complete loss of sight. After a further year the fundus showed optic atrophy, sheathing of the retinal vessels near the optic disc, and telangiectasis in the peripheral retina (Fig. $3 \mathrm{~A}$ ).

\section{FLUORESGENGE FUNDUS ANGIOGRAPHY}

\section{2 years after irradiation}

There was normal filling of the choroidal supply to the optic disc and cilio-retinal artery but no filling of the central retinal artery (Fig. $3^{\mathrm{B}}$ ). Some blood from the disc flowed back into the attenuated retinal veins on the optic disc and the adjacent retina which were seen ophthalmoscopically as red lines. A small leash of new vessels was seen at the centre of the disc, but small vessels were completely absent from the retina. A diffuse degeneration of the pigment epithelium was seen. In the centre of the irradiated area an accumulation of grey pigment was non-fluorescent; the obliteration of the choroidal vessels was much more extensive than this grey area.
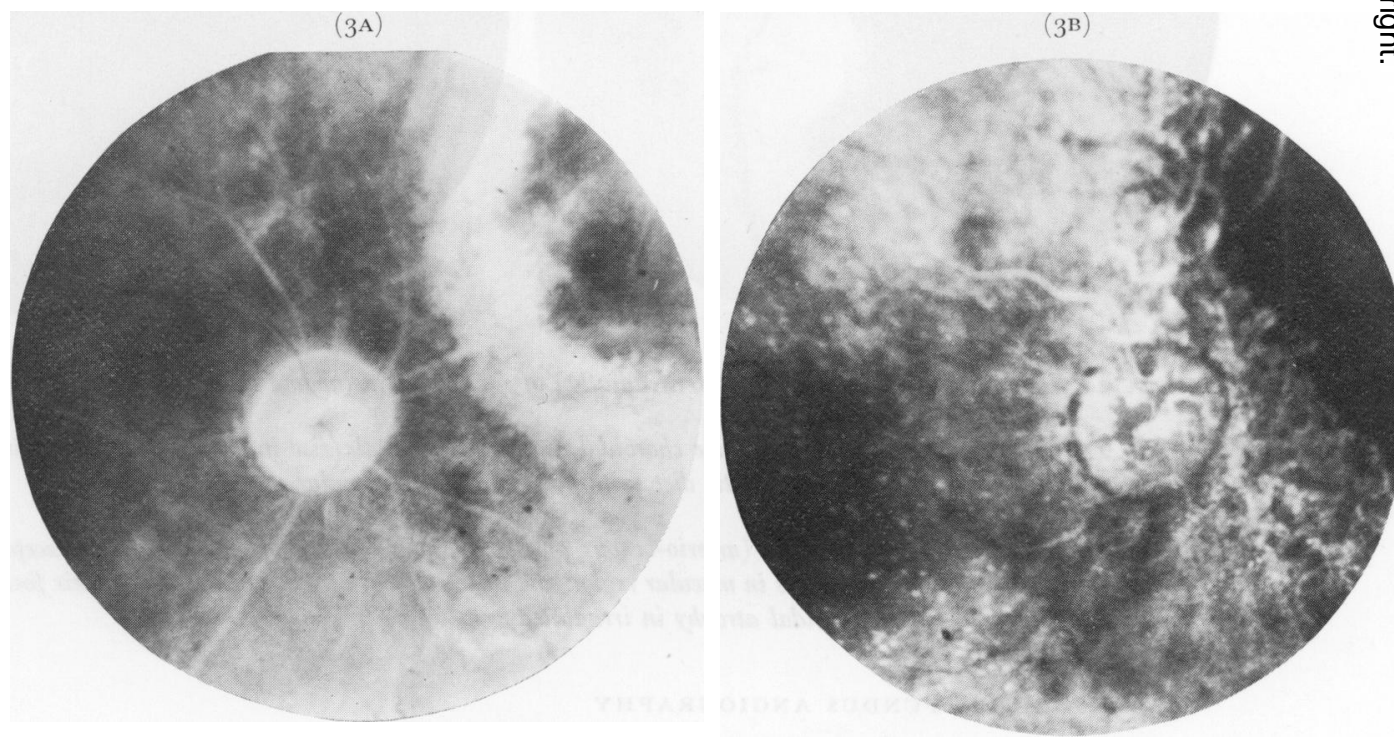

FIG. 3 Fundus of Case 3, 2 years after irradiation of malignant melanoma of choroid

FIG. 3A Photograph showing optic atrophy, sheathing of retinal vessels, new vessels on optic disc, and choroidal atrophy in superior nasal sector

FIG. 3 B Fluorescence angiogram (arterio-venous phase), showing normal filling of ciliary vessels in optic disc and cilio-retinal arteries; prominent choroidal fluorescence due to degeneration of pigment epithelium; choroidal atrophy in irradiated area; and flowing back of fluorescein into retinal veins from disc vessels 


\section{Discussion}

The findings in the three patients of the present series, in whom malignant melanoma of the choroid was treated by the application of Cobalt-6o plaques, show that post-radiation retinopathy may take the following form:

\section{(I) OBLITERATION OF THE RETINAL VESSELS}

This may be either focal retinal capillary obliteration (Fig. IB, D, E, H), retinal arterial branch occlusion (Figs ID, E; 2B), or central retinal artery occlusion (Fig. 3A, B). The susceptibility to obliteration of the retinal vessels is variable. The capillaries are most susceptible, the smaller arterioles less so, and the main arterioles are still less susceptible. The retinal veins do not seem to show a significant degree of susceptibility to occlusion.

Martin and Reese (1945) considered acute occlusion of the arteries and veins to be a late occurrence. Central retinal vein thrombosis was reported by Renard and Duriez (1949) and Cogan (1950). Cogan (1958) thought that occlusion of the central retinal vessels and direct damage to the retina were infrequent and occurred only with amounts of radiation in excess of that necessary to cause lens changes. The present study does not support Cogan's views, because in all three cases the lens was perfectly transparent and no anterior segment ocular lesion was seen.

The vascular obliteration is produced by the endothelial damage due to radiation. In postradiation retinopathy, the primary lesion responsible for the retinopathy is retinal vascular obliteration, all the other features being secondary to this and to the retinal ischaemia thus produced.

\section{(2) MIGROANEURYSMS}

These are usually situated in the area where there is occlusion of capillaries and most commonly at the stumps of the occluded vessels (Figs ID, E, H; 2B). Microaneurysms were seen in all cases of the present series as well as by Gass (1968) in his two cases.

\section{(3) REtinal telangiegtases AND NeOVASGularization}

These are situated on the retina (Fig. IE) or on the surface of the optic disc (Figs 2 and 3) and they leak fluorescein, thereby indicating that they are abnormal vessels.

According to Martin and Reese (1945), a possible factor in the formation of telangiectases and new vessels is atresia of a small portion of the normal smaller veins and capillaries as a result of irradiation, with consequent dilatation of the vessels to provide collateral circulation. Stallard (1966), however, described these telangiectatic vessels as small arterioles. In the present study these were seen to involve mainly the venous side of the circulation.

Telangiectases in the skin 4 years after irradiation have also been reported by Matas (1925).

\section{(4) COTTON-WOOL SPOTS}

In the past these were erroneously called "soft exudates". They are due to acute focal occlusion of small retinal arterioles, producing infarcts in the retina (Fig. IA, B, C, D, E). They disappear within 4 to 12 weeks, leaving no trace.

\section{(5) White RETINAL DEPOSITS}

These so-called "hard exudates" are frequently seen, particularly in the macular region (Fig. IC). They were reported by Stallard (1933, 1936, 1959, 1961, 1966) to resemble "circinate retinopathy" and to occur mainly in the perimacular region. These white deposits represent lipid material, formed by the breakdown of degenerate retinal neural tissue, most of it phagocytosed by the microglial macrophages and lying deep to the retinal vessels. These are indicative of interference with the oxidation mechanism in the retina (Dixon, 196I) and thus occur in any lesion associated with ischaemia and anoxia of the retina. 
These are mostly superficial retinal haemorrhages (Fig. IA, B, C, D, E, G, H) and represent a small retinal vascular occlusive phenomenon.

(7) RETINAL OEDEMA

This is due to infarction or ischaemia of the area of the retina involved by vascular occlusion (Fig. IF). Involvement of the macular region may produce cystoid macular oedema and degeneration (Fry, I952; Gass, 1968).

(8) SHEATHING OF LARGE RETINAL VESSELS

This occurs when these vessels are occluded (Figs 2 and 3 ). In this series none of the occluded vessels showed any circulation and the arteries were more commonly affected than the veins. Howard (1966) found that the sheathing and occlusion of the arteries began in the posterior pole as in the present series.

\section{(9) PERIVASGULitis}

The retinal arteries and veins in Case I showed evidence of segmental perivasculitis with slightly distended and irregular lumina in the same area (Fig. IC, F, I). The vascular occlusion had occurred in the recent past, and the changes were mole marked in the veins than in the arteries. Perivasculitis may be one of the factors responsible for the later sheathing of the vessels.

\section{(IO) OPTIC DISC CHANGES}

These involve primarily the vessels in the superficial nerve fibre layer which are derived from the retinal circulation. The deeper vessels in the prelaminar layer of the optic disc, which are of choroidal origin (Hayreh, 1969), are not involved and this is also the case with the cilio-retinger arteries (Figs ID, 2B, 3B). This indicates that the vessels of choroidal origin in the disc and the cilio-retinal arteries are not involved by radiation which affects only the retinal vessels or their derivatives. This indicates that the retinal vessels are the most susceptible to radiation damage. Optic atrophy, when seen, is secondary to obliteration of either the central retinal artery (Fig. 3A) or the vessels of the surface layer in the disc and retina (Fig. 2A), and is not due to damage to the nerve fibres. No disc oedema was seen in the present series, but when it occurs it is most probably of the ischaemic type and resembles the retinal oedema seen in these cases.

VITREOUS HAEMORRHAGES

These have been reported in rare cases (Stallard, 1959, 1961, 1966; Howard, 1966), but were not seen in the present series.

\section{(12) RETINAL DETAGHMENT}

This has been observed after irradiation by Ammann (1906), Martin and Reese (1942), and Stallard (1959). According to Martin and Reese (1942) it is due to shortening of the retina through contracture of scar tissue.

In the area of irradiation, the pigment of the malignant melanoma itself is unaffected by $\mathcal{N}$ radiation; it remains as a grey mass after the death of the lesion (Fig. 3A) but its blood vessels are completely destroyed. This changes its fluorescence angiographic pattern, i.e. it is fluorescent when active but becomes non-fluorescent after irradiation (Hayreh, 1970). In addition the normal choroidal bed around it also shows obliteration, the extent being inversely proportional to the size of the vessels, i.e. the choriocapillaris is the most affected and the normal large choroidal vessels are the least affected (Figs 2B, 38). This 
leads to much more extensive obliteration of the choriocapillaris than of the large choroidal vessels around the site of irradiation. The overlying pigment epithelium degenerates over the degenerated choriocapillaris. In contrast to this, the choroid and the pigment epithelium in the areas of post-radiation retinopathy usually show no noticeable change. In the present series, only Case 3 showed atrophy of the pigment epithelium which could be an extension of the atrophy involving the irradiated zone.

The latent period between the irradiation of the eye and the appearance of the retinopathy is a significant factor. The latent period simply reflects the time which elapses before the changes initiated by irradiation become sufficiently gross to be apparent; it is a stage in a continuous series of events (Duke-Elder, 1954). The longer the follow-up, the more extensive are likely to be the vascular obliteration and the retinopathy, as is demonstrated by the first case in this series. The observations of Ghee (ig68), however, do not lend full support to this supposition, because in some cases he described lesions which were stationary for some years. In the three cases of the present series, retinopathy first appeared 8, 22, and 12 months respectively after the irradiation. Changes were noticed after 3 to 6 months by Howard (1966), 6 to 8 months by Martin and Reese (1945), 8 months to 3 years by Chee (1968), 5 months to $7 \frac{1}{2}$ years (average 2 to 3 years) by Stallard (1966), and 12 months or more by Perrers-Taylor and others (1965).

Two histopathological reports of irradiated eyes are available in the literature (PerrersTaylor and others, 1965; Howard, 1966). Prof. Norman Ashton, in an eye removed 18 months after the irradiation of a squamous cell carcinoma of the upper eyelid, found retinal atrophy particularly involving the inner layers, with normal visual cells, pigment epithelium, and choroid (Perrers-Taylor and others, 1965). Howard (1966), in 21 eyes excised after irradiation for retinoblastoma, found sclerosis and shrinkage of the choroidal vessels, retinal atrophy, and thickening and hyaline degeneration of walls of the retinal arterioles in eleven eyes. The case of Perrers-Taylor and others (1965), in which the atrophic changes were confined to the inner retinal layers, would further confirm that the retinopathy is primarily the result of involvement of the retinal vessels; the presence of hyaline degenerative changes in the retinal arterioles seen by Howard (1966) corroborates these conclusions. The retinal atrophy is thus of vascular origin and not due to the direct involvement of the nervous tissue.

According to Perrers-Taylor and others (1965), the retinal changes are arteriosclerotic in type. The present study indicates that post-radiation retinopathy is a form of retinal vascular occlusive disorder, involving the fine retinal vessels first, and in all cases the capillaries and in some the main retinal vessels, particularly the arteries. The fluorescence angiographic pattern of this type of retinopathy is very similar to that seen in old retinal venous occlusion, diabetic retinopathy, circinate retinopathy, Eales's disease, hypertensive retinopathy, retinal telangiectasis (Coats's disease), and other conditions associated with retinal vascular occlusion.

\section{Summary}

Three patients with choroidal malignant melanoma treated with a Cobalt-6o applicator, who developed post-radiation retinopathy and marked loss of vision, were studied by fluorescence angiography. The retinopathy consisted of obliteration of the retinal vessels, microaneurysms, telangiectases and neovascularization, cotton-wool spots, white retinal deposits, retinal haemorrhages, retinal oedema, sheathing of big retinal vessels, perivasculitis, optic atrophy, vitreous haemorrhages, and (very rarely) retinal detachment. 
Post-radiation retinopathy represents a retinal vascular occlusive disorder secondary to vascular obliteration produced after a latent period of many months or years of the radiation of ocular or extraocular lesions.

I am grateful to Mr. A. McDonald for the illustrations.

\section{References}

ammann, e. (1906) Correspbl.f. Schweiz. Aerzte, 36, 487 (Cited by Duke-Elder, 1954) BEDFORD, M. A., BedotTo, C., MACFAUl, P. A. (1970) Brit. F. Ophthal., 54, 505 CHEE, P. H. Y. (1968) Amer. F. Ophthal., 66, 86o

cogan, D. G. (1950) 7. Amer. med. Ass., 142, 145 (1958) New Engl. 7. Med., 259, 517

DIxon, K. c. (1961) Amer. F. Path., 39, 65

DUKE-ELDER, s. (1954) “Text-Book of Ophthalmology", vol. 6, pp. 6532, 6555. Kimpton, London FRY, W. E. (1952) Trans. Amer. Acad. Ophthal. Otolaryng., 56, 888

GASS, J. D. M. (1968) Arch. Ophthal. (Chicago), 80, 606

HAYREH, s. s. (1969) Brit. 7. Ophthal., 53, $72 \mathrm{I}$

(1970) Ibid., 54, 145

hOWARD, G. M. (1966) Arch. Ophthal. (Chicago), 76, 7

MAGFAUl, P. A., and BEDFORD, M. A. (1970) Brit. J. Ophthal., 54, 237

mARTIN, H., and REESE, A. B. (1942) Arch. Ophthal. (Chicago), 27, 40

$\longrightarrow$ (1945) Ibid., 33, 429

MATAS, R. (1925) Amer. F. Roentgenol., 13, 37

MOORE, R. FOSTER (1935) Trans. ophthal. Soc. U.K., 55, 3

PERrers-taylor, M., BRINKLey, D., and Reynolds, T. (1965) Acta radiol. Ther., Phys., Biol. (Stockh.

3, 43 I

PILlat, A. (1935) Klin. Mbl. Augenheilk., 94, 384

RENARD, G., and DURIEz, J. c. (1949) Bull. Soc. Ophtal. Fr., p. 776

StAllard, H. B. (1933) Brit. F. Ophthal., Monograph Supplement No. 6, "Radiant Energy as

(a) a Pathogenic (b) a Therapeutic Agent in Ophthalmic Disorders", p. 70

(1936) Brit. med. F., 2, 962

- (1959) Trans. ophthal. Soc. U.K., 79, 373

- (1961) Ann. roy. Coll. Surg. Engl., 29, 170

- (1966) Brit. J. Ophthal., 50, 147 